\title{
Behavior of Surface Integrity in Cylindrical Plunge Grinding Using Different Cooling Systems
}

\author{
Leonardo Roberto Silva*, Mariana Faccio Mattos, Lucimar Venâncio Amaral, \\ Elaine Carballo Siqueira Corrêa, Joel Romano Brandão
}

Department of Materials Engineering, CEFET-MG, Belo Horizonte, MG, Brazil

Received: December 8, 2010; Revised: March 13, 2011

\begin{abstract}
The superficial texture of the material can exert a decisive influence on the application and performance of the machined component. The conventional fluids used in grinding processes are environmental risk and can also be dangerous to the health. The disposal of these toxic fluids is expensive and the contamination in the proximities of the machines can present risks to the health for the personnel in the shop floor. This paper analyzes the performance of the minimum quantity lubricant (MQL) technique and compares it with the conventional cooling method, developing an optimized fluid application method using a specially designed nozzle, through which a minimum amount of oil is sprayed in a compressed air flow. This paper also explores and discusses the concept of the MQL in the grinding process of hardened AISI 4340 steel. The performance of the MQL technique in grinding was evaluated based on an analysis of the surface integrity (roughness, microstructure and microhardness). As a result, it was realized that the MQL technique provides very similar characteristics to conventional process and can be applied in industry, thus contributing to an environment friendly manufacturing.
\end{abstract}

Keywords: grinding, minimum quantity lubricant-MQL, surface integrity and cutting fluids

\section{Introduction}

In recent years, energy consumption, air pollution and industrial waste have been the focus with special attention by public authorities. The environment has become one of the most important subjects within the context of modern life, since its degradation directly impacts human race. Driven by pressure from environmental agencies, politicians have drawn up increasingly strict legislation aimed at protecting the environment and preserving natural energy resources. These combined factors have led the industrial sector, research centers and universities to seek alternative production processes, creating technologies that minimize or avoid the production of environmentally aggressive residues.

However, the advantages caused by the cutting fluids have been questioned lately, due to the several negative effects they cause. When inappropriately handled, cutting fluids may damage soil and water resources, causing serious loss to the environment. Therefore, the handling and disposal of cutting fluids must obey rigid rules of environmental protection ${ }^{1-2}$.

Emulsion-based cooling fluids for machining are still widely used in large quantities in industrial metal-working processes, generating high consumption and disposal costs and harming the environment. The growing need for environmentally correct production techniques and the rapidly rising cost involved in the disposal of cutting fluid justify the demand for an alternative to the grinding process with fluid. In the last decade, however, the goal of researches has been to strongly limit the use of cooling and/or lubricating fluids in metalworking production processes. Dry machining and minimum quantity lubricant (MQL) machining have caught the attention of researchers and technicians in the field of machining as an alternative to traditional fluid application systems. The drastic reduction or even the complete elimination of this fluid can undoubtedly lead to higher temperatures in the process, causing reduced cutting tool life, loss of dimensional and geometrical precision of workpieces and variations in the thermal behavior of machine-tools. When abrasive tools are used, a reduction in cutting fluid may make it difficult to keep the grinding wheel with its pores clean, favoring the tendency for clogging and thus strongly contributing to the aforementioned negative factors ${ }^{2-7}$.

For the companies, the costs related to cutting fluids represent a large amount of the total machining costs. Several research workers state that the costs related to cutting fluids is frequently higher than those related to cutting tools. Consequently, elimination on the use of cutting fluids, if possible, can be a significant economic incentive. Considering the high costs associated with the use of cutting fluids and projected escalating costs when the stricter environmental laws are enforced, the choice seems obvious. Because of them some alternatives have been sought to minimize or even avoid the use of cutting fluid in machining operations. Some of these alternatives are dry machining and machining with minimum quantity of lubricant $(\mathrm{MQL})^{2,4,7,8}$.

Confirming the trend for environmental concerns triggered by the use of cutting fluids in machining processes, as reported by several researchers and machine tool manufacturers, strong emphasis today focuses on environmentally correct technologies aimed at preserving the environment and at conforming to the ISO 14000 standard. On the other hand, despite persistent attempts to completely eliminate cutting fluids, in many cases cooling is still essential to the economically viable service life of tools and the surface qualities required. This is particularly true when strict tolerance and highly exact dimensions and shapes are required, or when the machining of critical difficultto-cut materials is involved. Minimum quantity of lubricant, in these cases, is an interesting alternative because it combines the functionality of cooling with an extremely low consumption of lubricant (usually $<80 \mathrm{~mL} / \mathrm{h}$ ). The minimization of cutting fluid has taken on increasing relevance over the last decade ${ }^{1,4,9-11}$.

Significant progress has been made in dry and semidry machining recently and MQL machining, in particular, has been accepted as a successful semidry application because of its environmentally 
friend characteristics. Some good results have been obtained with this technique ${ }^{12}$. Dhar et al. ${ }^{13}$ used this technique in turning process and concluded that, in some cases, MQL has been shown to be better than flood cooling.

The grinding process requires a considerable amount of energy per unit volume to remove material. During the process, this energy is transformed into heat, which concentrates in the cutting region. High temperatures can cause several types of thermal damage to the workpiece, such as superficial burning, microstructural modifications, and surface and subsurface heating of the piece, which allows for superficial tempering and re-tempering of a material (in hardened steel machining) with the formation of non-softened martensite, generating undesirable residual tensile stresses and thus reducing the ultimate fatigue strength of the machined component. Moreover, uncontrolled thermal expansion and contraction of the workpiece during grinding contribute to errors in the dimension and shape of the final component, these phenomena leading mainly to errors in circularity. The grinding rates utilized today are limited by the maximum temperatures permissible in the grinding process. When these temperatures are exceeded, they may lead to deterioration of the workpiece dimensional quality. Thus, the sources giving rise to residual stress on the machined surface can be phase transformation, thermal stress due to irregular heating and cooling of the surface layer, and mechanical strain ${ }^{14-18}$

The present investigation aims at evaluate the performance of the MQL system compared to conventional cooling, applied in very small flow rates as an environmentally correct alternative to the cutting fluid utilized in cylindrical plunge grinding. The small amount of lubricant is pulverized in a compressed air flow, reducing the undesirable effects involved in using cutting fluids. The evaluation of the MQL technique in the grinding process consisted of analyzing the surface integrity (roughness, microstructure and microhardness).

\section{Experimental Procedure}

The material used in these tests was the hardened and tempered ground AISI 4340 steel $(0.4 \% \mathrm{C} ; 1.8 \% \mathrm{Ni} ; 0.8 \% \mathrm{Cr} ; 0.23 \% \mathrm{Mo}$; $0.68 \% \mathrm{Mn} ; 0.23 \% \mathrm{Si}$ ), with an average hardness value of $52 \mathrm{HRc}$, and external diameter and length of 36 and $42 \mathrm{~mm}$, respectively. Classified as a hardened steel, it is employed in the manufacture of components, which require a good combination of mechanical strength and toughness.

The tests were carried out using aluminum oxide $\left(\mathrm{Al}_{2} \mathrm{O}_{3}\right)$ grinding wheels with the following characteristics: $(355.6 \times 50.8 \times 127-\mathrm{FE}$ $38 \mathrm{~A} 60 \mathrm{KV}$ ) manufactured by Norton. The dressing operation was kept constant, using a diamond multiple dresser that did not influence the output variables of the process.

A series of preliminary tests were carried out to determine the best lubricant and compressed air flow rate, as well as the best choice of the various types of lubricants using the MQL technology. The LB 1000 lubricant supplied by the MQL equipment manufacturer presented the best performance; therefore, all the results reported here involve this type of lubricant. A synthetic emulsion in a 5\% concentration was used in the flooded cooling condition. The maximum flow rate supplied by the pump and by the machine original nozzle was $11 \mathrm{~L} / \mathrm{min}$.

The main input parameters (grinding wheel speed $\left(\mathrm{v}_{\mathrm{s}}\right)$, feed rate $\left(\mathrm{v}_{\mathrm{f}}\right)$, workpiece speed $\left(\mathrm{v}_{\mathrm{w}}\right)$, depth of cut (a) and spark-out time $\left(\mathrm{t}_{\mathrm{s}}\right)$ ) were selected based on preliminary tests. The cutting conditions selected after testing preliminary to the definitive tests were: $\mathrm{v}_{\mathrm{s}} \cong 33 \mathrm{~m} / \mathrm{s} ; \mathrm{v}_{\mathrm{f}}=1 \mathrm{~mm} / \mathrm{min} ; \mathrm{v}_{\mathrm{w}} \cong 20 \mathrm{~m} / \mathrm{min}$ (average speed) and $\mathrm{t}_{\mathrm{s}}=12$ seconds. These parameters were kept constant throughout the experiments. The values were obtained after five stages for each analyzed condition. Each grinding stage removed $1 \mathrm{~mm}$ of diameter of workpiece, with a feed rate plunge of $1 \mathrm{~mm} / \mathrm{min}$, providing at the end of the process a reduction of $5 \mathrm{~mm}$ in diameter.
The equipment used to control the MQL was Accu-lube provided by the manufacturer ITW Chemical Products Ltd, which uses an oil supply pulse system and allows the air and lubricant flow rates to be adjusted separately. Figure 1a shows the control unit of the MQL equipment fixed to the grinding machine where the lubricant dose and air flow rate adjustment are carried out. The nozzle was placed at a distance of about $35 \mathrm{~mm}$ from the grinding wheel workpiece interface as shown in Figure 1b. In order to accurately measure the flow of compressed air, a turbine type flow meter was bought and calibrated to a pressure of $8 \mathrm{kgf} . \mathrm{cm}^{-2}$. The working pressure used in the tests was $6.5 \mathrm{kgf.cm}{ }^{-2}$. Figure 2 shows the nozzle developed and used during the tests of the MQL technique in the grinding process.

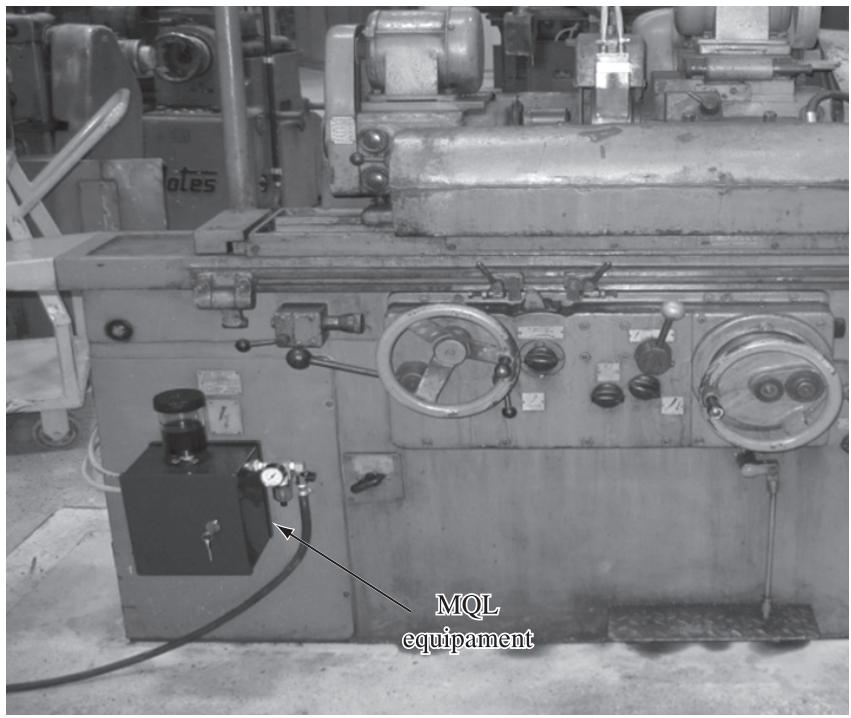

(a)

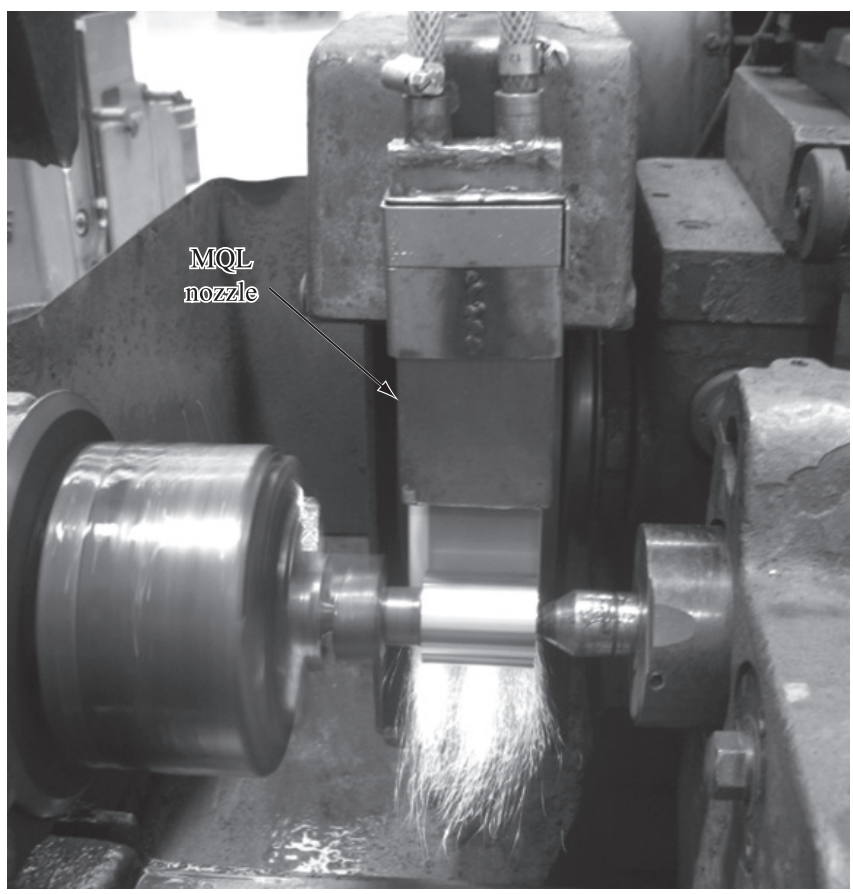

(b)

Figure 1. a) MQL equipment (Accu-Lube) fixed to the grinding machine, where the lubricant dosage and air flow rate adjustment are carried out; and b) setup showing the location of nozzle relative to the grinding wheel and workpiece. 


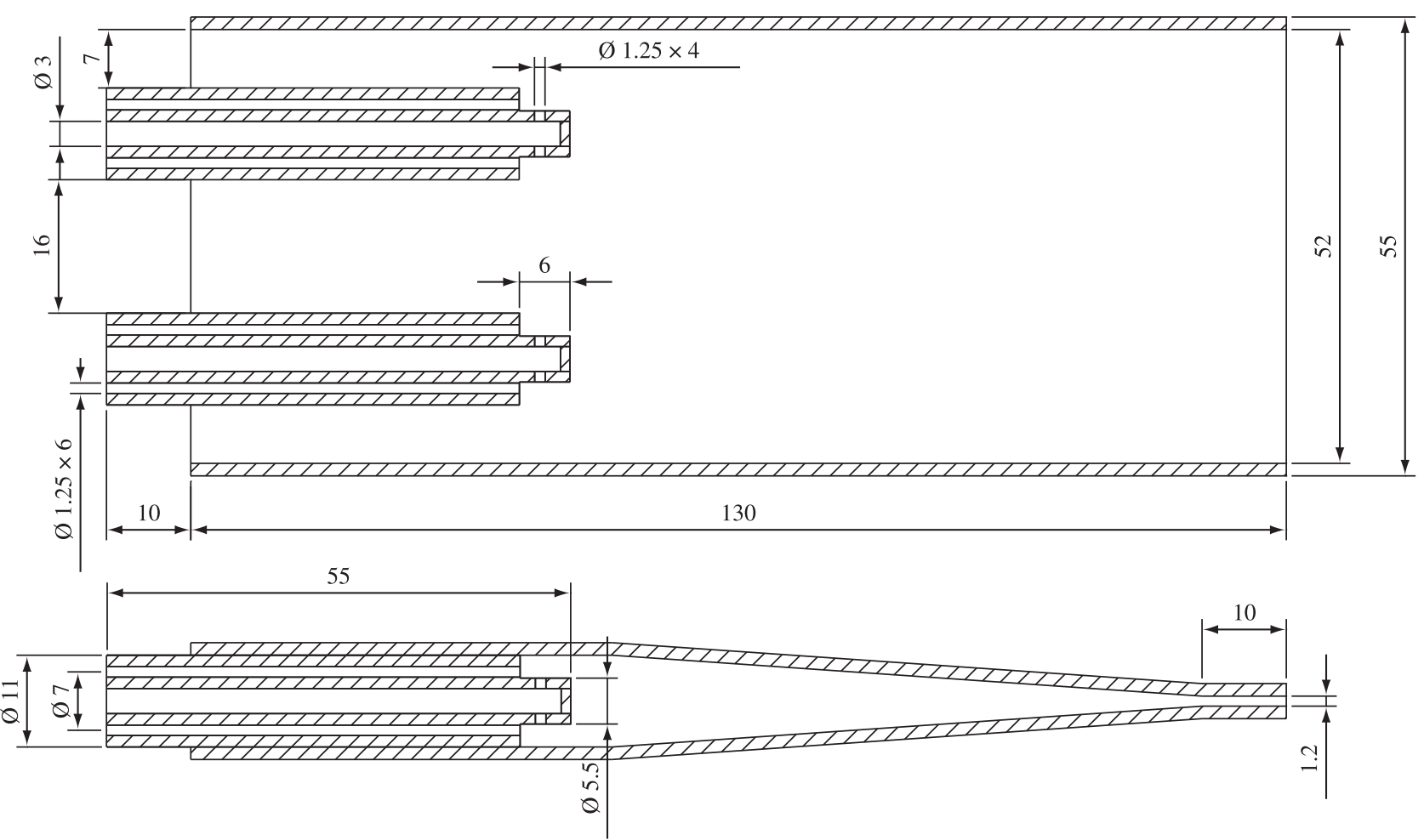

Figure 2. Design of nozzle (mm) used in the MQL tests.

After defining the cutting parameters, the array of experiments for the definitive tests using aluminum oxide grinding wheel $\left(\mathrm{Al}_{2} \mathrm{O}_{3}\right)$ was planned, as shown in Table 1. During the final tests, dry cutting was also evaluated in order to compare the behavior of the output variables analyzed with the three conditions of cooling systems (conventional, MQL and dry cutting).

The surface roughness was measured by adjusting the profilometer to a cut-off length of $0.8 \mathrm{~mm}$. At the end of each test, the average of the surface roughness values, $R_{a}$, were measured at 8 different points approximately $45^{\circ}$ equidistant from each other.

Scanning electron microscopy (SEM) was used to analyze possible damages caused by thermal and mechanical forces on the material surface. The scanning electron microscope is a highly versatile device which allows different types of analyses. The main advantages of the SEM in relation to an optical microscope are its resolution and focal depth. The values of microhardness were obtained using a digital microhardness tester Leitz, with load of $0.2 \mathrm{kgf}$ and application time of 30 seconds, at a distance of $70 \mu \mathrm{m}$ from the surface of the samples. The microhardness considered in the analysis was the average of four measurements in each sample.

\section{Results and Discussion}

The results described below refer to the best cutting and cooling conditions found in the cylindrical plunge grinding of hardened AISI 4340 steel for the parameters evaluated here.

It is well known that the surface finish can significantly affect the mechanical strength of components when they are subjected to fatigue cycles.

Figure 3 compares the mean values of the $\mathrm{R}_{\mathrm{a}}$ parameter $(\mu \mathrm{m})$ with the $\mathrm{Al}_{2} \mathrm{O}_{3}$ grinding wheel under conventional cooling against those obtained with the MQL technique. The values were obtained after five stages for each analyzed condition, in which each grinding
Table 1. Array of experiments in the definitive tests with aluminum oxide grinding wheel.

\begin{tabular}{cccc}
\hline Trials & $\begin{array}{c}\text { Lubricant } \\
\text { flow rate } \\
\text { LB } 1000(\mathrm{~mL} / \mathrm{h})\end{array}$ & $\begin{array}{c}\text { Compressed } \\
\text { air speed } \\
(\mathrm{m} / \mathrm{s})\end{array}$ & $\begin{array}{c}\text { Cutting fluid } \\
\text { flow rate } \\
(\mathrm{L} / \mathrm{min})\end{array}$ \\
\hline 1 & 20 & 26.40 & - \\
2 & 20 & 19.80 & - \\
3 & 40 & 26.40 & - \\
4 & 40 & 19.80 & - \\
5 & 60 & 26.40 & - \\
6 & 60 & 19.80 & - \\
7 & 80 & 26.40 & - \\
8 & 80 & 19.80 & 11 \\
9 & - & - & - \\
& & & -
\end{tabular}

stage removed $1 \mathrm{~mm}$ of diameter of workpiece, with a feed rate plunge of $1 \mathrm{~mm} / \mathrm{min}$.

Surface finish is also an important index of machinability or grindability because the performance and the service life of the ground component are often affected by its surface finish, nature and extent of residual stresses and presence of superficial or subsuperficial microcracks. The roughness of a ground component is mainly influenced by size of abrasive grain, dressing conditions, feed rate, spark-out time and cooling conditions. The analysis of the results obtained with the conventional cutting fluid application system and with the MQL technique indicates that the application of cutting fluid by MQL technique led to satisfactory results in comparison to the conventional system, due to the more efficient penetration of the fluid into the cutting region. 


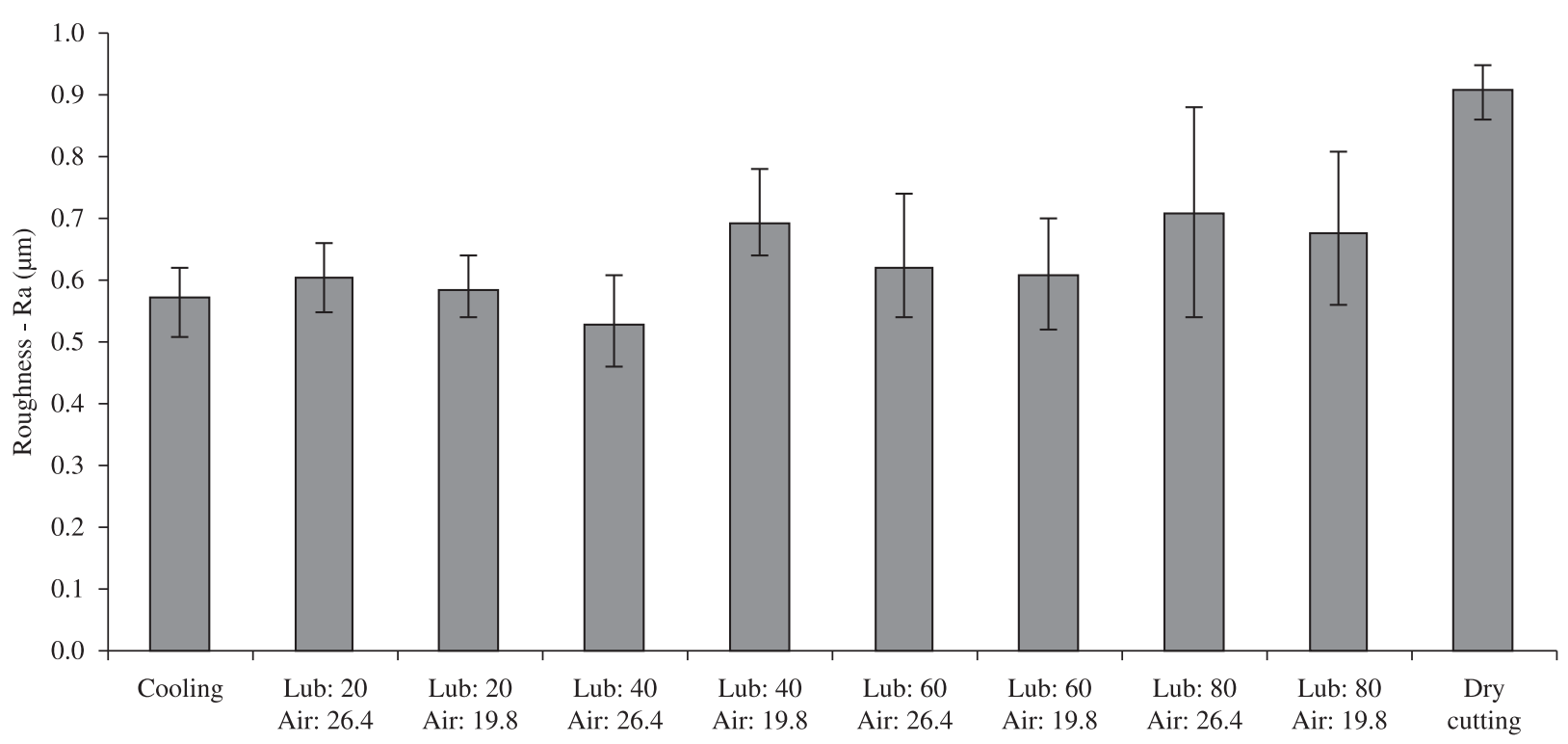

Figure 3. Roughness $\left(\mathrm{R}_{\mathrm{a}}\right)$ after 5 cycles of $1 \mathrm{~mm}$ in different cooling conditions with the $\mathrm{Al}_{2} \mathrm{O}_{3}$ grinding wheel (air: $\mathrm{m} / \mathrm{s}$; lubricant: $\mathrm{mL} / \mathrm{h}$ ).

In general, the MQL technique led to lower roughness values, probably because of the more effective lubrication and the cooling of the abrasive grains at the workpiece-wheel interface.

Efficient lubrication allows the chips to slide easier over the tool surface, resulting in a better superficial finish. The best performance of the MQL technique was the condition of lubrication and cooling air speed of $40 \mathrm{~mL} / \mathrm{h}$ and $26.4 \mathrm{~m} / \mathrm{s}$, respectively. In general, the emulsion has its basic feature efficient heat removal of the workpiece, but with a low lubrication system affecting the value of roughness.

Figure 4 shows the micrographs of sample cross-sections; illustrating possible subsurface alterations that took place in the samples when the $\mathrm{Al}_{2} \mathrm{O}_{3}$ grinding wheel was used with conventional cooling, dry condition, with the use of the MQL technique and also part of the sample heat treated.

All the energy spent in grinding is converted into heat in the grinding zone, which leads to higher temperatures and possible thermal damages in the workpiece. Several thermal damages may occur in grinding of quenched steel, including tempering and rehardening due to formation of fragile martensite if the grinding temperature is high enough to cause the reaustenitization. These damages can be avoided if the grinding process is carried out in such a way that the maximum temperature in the grinding zone is kept below the minimum value for reaustenitization, normally near the eutectoid temperature of the carbon steel and many alloy steels ${ }^{19}$.

Note that the superficial alterations produced by the various lubrication and cooling conditions were minimal, without significant differences between the conditions tested. Analyzing the microstructures, it can be noted that the quenched and tempered AISI 4340 steel shows martensite structure. The presence or not of this martensitic structure is a complex process, dependent on the heat treatments previously carried and the temperature heating and cooling time imposed by the cutting fluid.

It can be noticed that the micrographs have not presented significant subsurface alterations in all conditions tested. Probably, the amount of heat and plastic deformation that entered the workpiece during the grinding process regarding slight conditions of grinding was not sufficient to produce important subsurface alterations in the material microstructure. The microstructure under dry condition shows thinner martensitic structure in the subsurface.
This phenomenon is probably due to the occurrence of tempering as a result of a higher temperature and slow cooling. The damage to the surface integrity of a part can lead to acceleration of the fatigue process, change the resistance to abrasion and corrosion, or cause the emergence and growth of cracks.

The microstructure of the samples can be related to the values of microhardness. Figure 5 represents the variation in microhardness as a function of cooling conditions. The results related to dry cutting and heat treated material are also exhibited. Considering only the material submitted to quenching and tempering, needles of martensite and some plates of bainite can be observed (Figure 4a). In conventional cooling condition (Figure 4c), a strong presence of martensite is verified, which explains the increase in hardness of the material in the subsurface. In the dry condition (Figure 4b), a change in microstructure with the presence of tempered martensite is noted. In the other microstructures perceive the presence of martensite, resembling the condition with conventional cooling. The microhardness values were found relatively close, which proved not to be necessary to show the deviations range on the graphic.

In general, grinding operation of steels takes place after their heat treatment. Depending on the temperature of the cutting process, tempering or even annealing of the workpiece may occur during grinding, causing softening close to the finished surface. Note that in conventional cooling condition, the microhardness values are higher than the sample heat treatment only, without the influence of grinding process. For other conditions, there was a reduction in the value of microhardness, due to heat from the grinding process followed by slower cooling compared to conventional condition. Analyzing the dry grinding, it is noted that it has lower values of microhardness, which is detrimental to wear resistance. Loss of superficial hardness is a complex phenomenon relating to annealing of the martensitic structure and to carbon diffusion, and is dependent on the temperature and time involved in the cutting process.

Malkin ${ }^{14}$ stated that, in practice, it is interesting to combine the annealing behavior with a thermal analysis in order to predict the drop in hardness of the piece. Experimental results demonstrate that high temperatures and long periods of exposure of the workpiece to such temperatures, at low velocities or with longer contact lengths of the workpiece, lead to greater losses in hardness. 


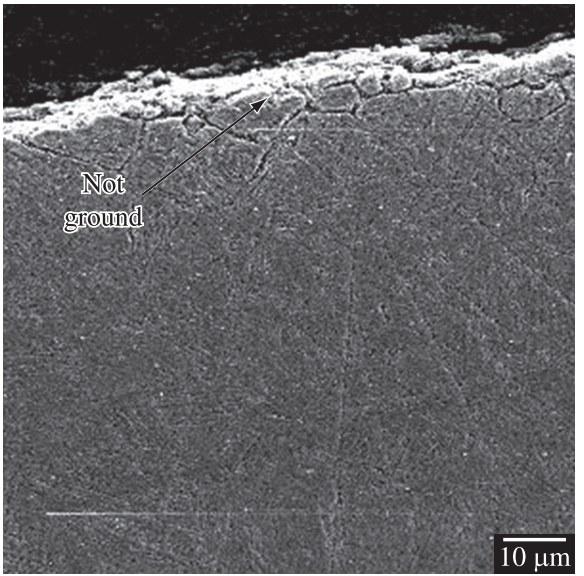

(a)

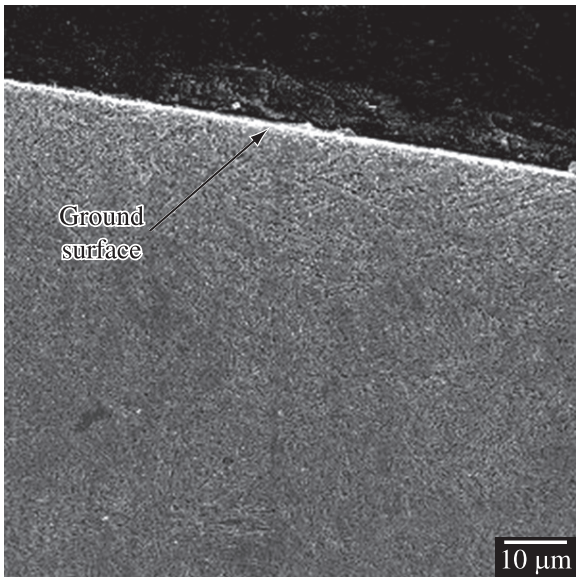

(d)

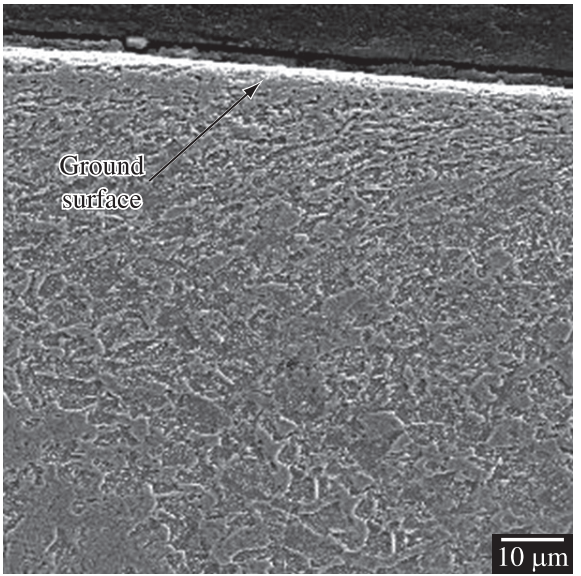

(b)

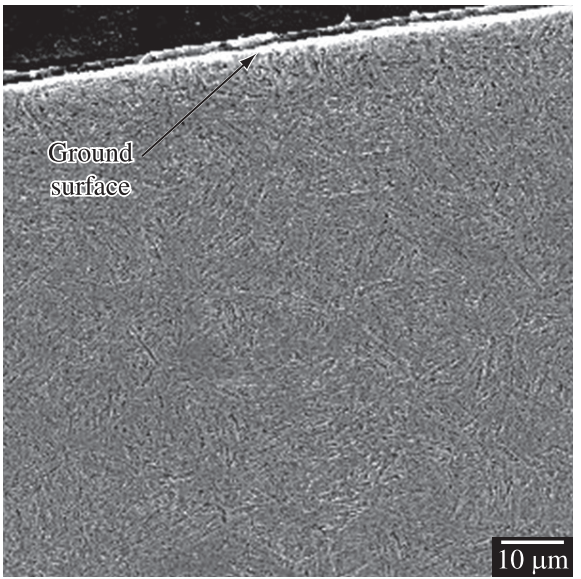

(e)

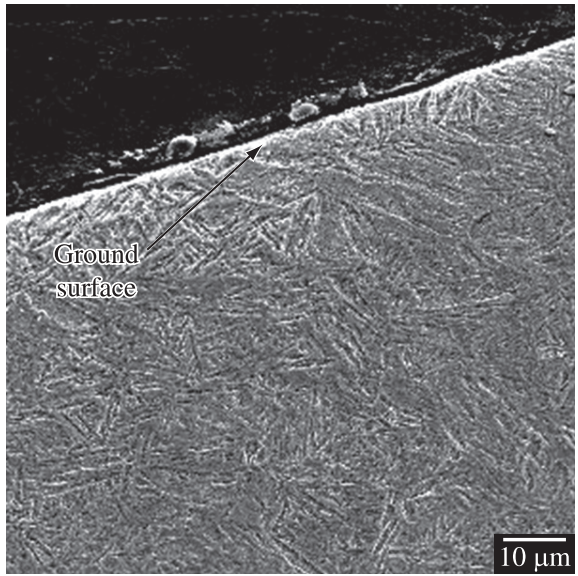

(c)

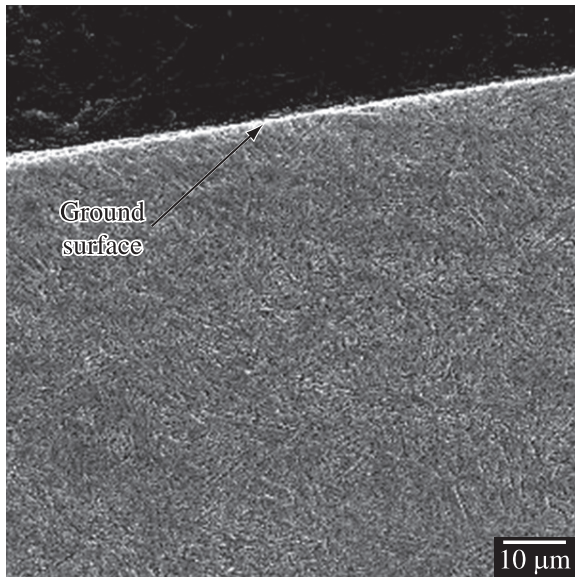

(f)

Figure 4. Subsurface microstructures obtained after 5 cycles of $1 \mathrm{~mm}$ in different cooling conditions - 1,000x. a) Heat treatment (not ground surface); b) dry cutting; c) conventional cooling; d) MQL (lubricant: $40 \mathrm{~mL} / \mathrm{h}$; air: $26.4 \mathrm{~m} / \mathrm{s}$ ); e) MQL (lubricant: $20 \mathrm{~mL} / \mathrm{h}$; air: $26.4 \mathrm{~m} / \mathrm{s}$ ); and f) MQL (lubricant: $60 \mathrm{~mL} / \mathrm{h}$; air: $26.4 \mathrm{~m} / \mathrm{s}$ ).

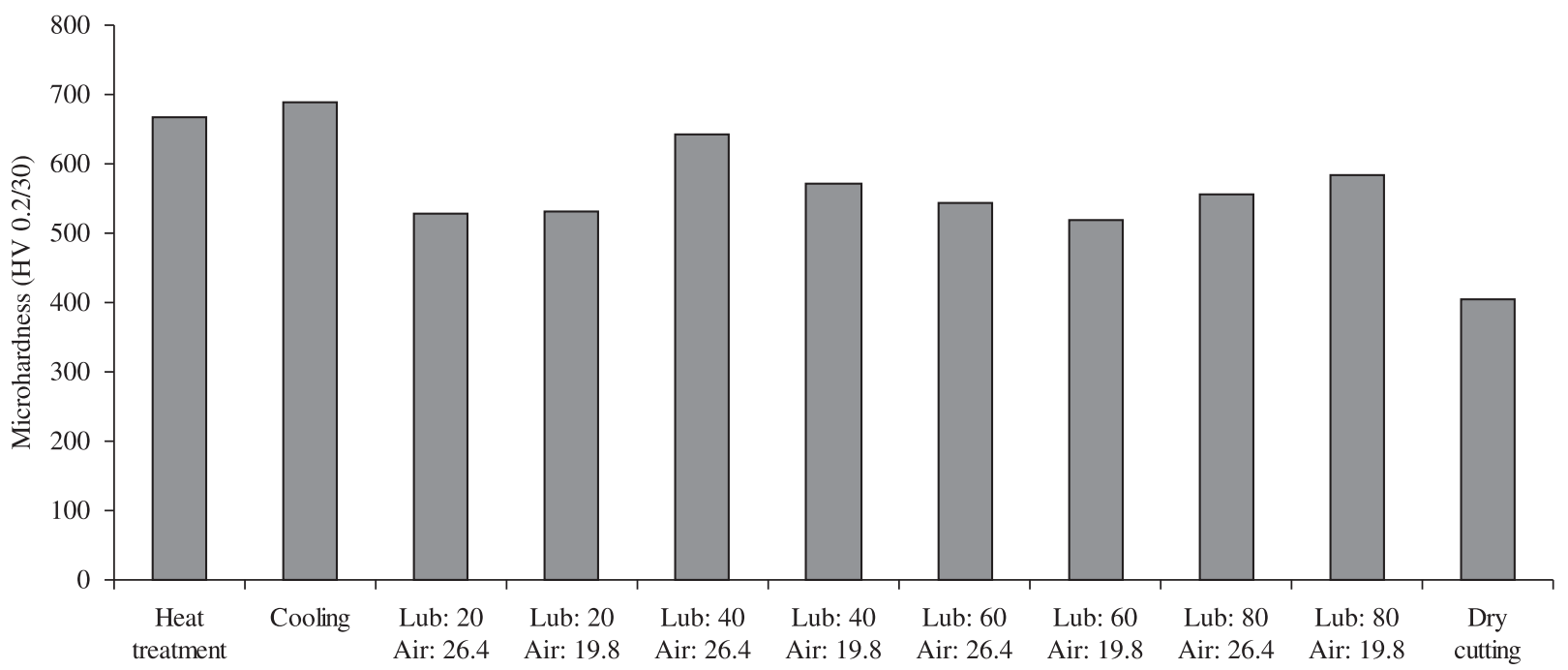

Figure 5. Variation of microhardness at a depth of $70 \mu \mathrm{m}$ from the surface in different cooling conditions after 5 cycles of $1 \mathrm{~mm}$. 


\section{Conclusions}

An analysis of the experimental data of this study led to the following conclusions regarding the cylindrical plunge grinding of hardened AISI 4340 steel:

- The MQL technique could be applied efficiently in the grinding process, providing environmentally correct and technologically relevant gains in cutting conditions tested;

- The use of MQL did not negatively affect the surface integrity;

- In some conditions, the Ra values were reduced with the use of MQL technique compared with conventional cooling method with the synthetic emulsion used, probably due to excellent properties of lubricity;

- No significant subsurface alterations in the microstructure were detected under conventional cooling and with MQL;

- The results obtained in the measurement of microhardness for different conditions of lubrication and cooling also showed no significant changes subsurface, except in dry cutting. These data confirm the observations made in the analysis of microstructure;

- The best overall performance when using the MQL technique was provided by the condition of lubrication and cooling ( air $=26.4 \mathrm{~m} / \mathrm{s}$ and lubricant $=40 \mathrm{~mL} / \mathrm{h}$ ); and

- The flow rates selected for application of MQL technique showed no dispersion of the mist, with a significant reduction in funding costs of disposing of the fluid, thus contributing to environmentally friendly manufacturing.

\section{Acknowledgments}

The authors would like to thank CNPq and FAPEMIG for funding this research. They also acknowledge the Department of Materials Engineering for his support during the experimental work.

\section{References}

1. Sokovic M and Mijanovic K. Ecological aspects of the cutting fluids and its influence on quantifiable parameters of the cutting processes. Journal of Manipulative and Physiological Therapeutics. 2001; 109(1-2):181-189.

2. Silva LR, Bianchi EC, Fusse RY, Catai RE, França TV and Aguiar PR. Analysis of surface integrity for minimum quantity lubricant $-M Q L$ in grinding. International Journal of Machines Tools \& Manufacture. 2007; 47:412-418. doi:10.1016/j.ijmachtools.2006.03.015

3. Sahm D and Schneider T. The production without coolant is interesting and must be more known. Machines and Metals Magazine. 1996; (367):38-55.

4. Klocke F and Eisenblatter G. Dry cutting. Cirp Annals. 1997: 46(2):519-526. doi:10.1016/S0007-8506(07)60877-4
5. Dunlap C. Should you try dry?. Cutting Tool Engineering. 1997; 49(1):22-33.

6. Novaski $\mathrm{O}$ and Dorr J. Machining without coolant. Machines and Metals Magazine. 1999; 399:18-27.

7. Machado AR and Diniz AE. Advantages and disadvantages of the use of the cutting fluids. In: Machining Congress. São Paulo; 2000.

8. Byrne $\mathrm{G}$ and Scholta E. Environmentally clean machining processes a strategic approach. Cirp Annals. 1993; 42(1):471-474. doi:10.1016/ S0007-8506(07)62488-3

9. Heisel U, Lutz D, Wassmer R and Walter U. The minimum quantity lubricant technique and its application in the cutting process. Machines and Metals Magazine 1998; (386): 22-38.

10. Schulz H. Trends in manufacturing technology at the threshold of the millennium. In: Fourth International Congress of High Technology Technological Innovations in the Manufacture; 1999; Piracicaba, Brazil. Piracicaba: Unimep; 1999

11. Dorr J. New perspectives in dry machining. In: Fourth International Congress of High Technology - Technological Innovations in the Manufacture; 1999; Piracicaba, Brazil. Piracicaba: Unimep; 1999.

12. Tonshoff HK and Spintig W. Machining of holes developments in drilling technology. Cirp Annals. 1994; 43(2):551-561. doi:10.1016/S00078506(07)60501-0

13. Dhar NR, Islam MW, Islam S and Mithu MAH. The influence of minimum quantity of lubrication $(M Q L)$ on cutting temperature, chip and dimensional accuracy in turning AISI-1040 steel. Journal of Material Processing Technology. 2004; 171:93-99. doi:10.1016/j. jmatprotec.2005.06.047

14. Malkin S. Grinding mechanisms \& grinding temperatures and thermal damage. In: Malkin S, editor. Grinding Technology: Theory and Applications of Machining with Abrasives. Chichester: Ellis Horwood Limited; 1989. p. 108-171.

15. Shaw MC. Heat-affected zones in grinding steel. Cirp Annals. 1994; 43(1): 279-282. doi:10.1016/S0007-8506(07)62213-6

16. Kovacevic R and Mohan R. Effect of high speed grinding fluid on surface grinding performance. In: SME Technical paper MR95-213. 1995. p. 919-931.

17. Abrao AM and Aspinwall DK. The surface integrity of turned and ground hardened bearing steel. Wear. 1996; 196:279-284. doi:10.1016/00431648(96)06927-X

18. Ebbrell S, Woolley NH, Tridimas YD, Allanson DR and Rowe WB. The effects of cutting fluid application methods on the grinding process. International Journal of Machine Tools \& Manufacture. 2000; 40(2):209-223. doi:10.1016/S0890-6955(99)00060-7

19. Malkin S and Guo C. Simulation, optimization and control of cylindrical grinding. In: Machining Congress. Sao Paulo; 2002. 